she was calm, cleanly, and pleasant, perfectly satisfied with her situation, and grateful for all favors. She slept quietly, gained flesh, and in six weeks was perfectly restored.

A hale, robust man, of abstemious habits and very laborious, was attacked, after an unusual mental effort of some dilys continuance, wilh mania ferox. His violence was extrone; he was entirely unconscious where he was, or what was done for him, and who adiministered to his wants. He was repeatedly bled largely, took drastic cathartics, and the most rigid diet. When he came under my care, after being in this condition a month, his appearance was haggand, emaciated, pale and bloodless-his extremities cold, and the surface of his body covered with sores, the effect of his violence. He was dangerous to approach, as his fury extended alike to all who came in his way. He was placed under a directly opposite mode of treatment. Tonics and narcotics, with wine, were administered with a liberal hand. His dict was animal food, bread, tea, coffee, and vegetables, with fruits. He ate freely, and was always hungry. In ten days he was calm and rational, his feelings composed and tranquil, his sleep quiet and refreshing. His recovery was surprisingly rapid. In four weeks his insanity was gone, and he had no remains of disease but the effects of the vigorous reduction to which he was in the first instance subjected.

Cases of this description are almost daily coming under my observation, and the result of the treatment has taught me an important practical lesson in insanity-not to mistake excessive nervous action for inflammation, nor be led to consider the great muscular power of the maniac any proof of the strength and vigor which requires active depletion.

W.

June, 1837.

\title{
CORROBORATIVE TESTIMONY IN FAVOR OF LARGE DOSES OF OPIUM IN RUEUMATISM.
}

[Communleated for tho Boston Nedical aud Surgical Jouruas.]

As we are often at a loss, when any new medicine or new treatment of any particular disorder is recommended, whether to employ it or not, being very often disappointed in such cases, it is highly important that all the evidence for or against such medicine or treatment should be communicated. One or two or half a dozen successful terminations of a disorder, do not always establish the fact that the treatiment made use of in such disorder was the most judicious.

These ideas suggested themselves by reading Dr. Webb's highly valuable Prize Dissertation upon Rheumatism, and afterwards comparing his views in regard to its cure with ny own experience. Having been very friendly to the use of opium, either alone or in combination with other medicine, as a remedial agent in many complaints, it occurred to my mind that it would be a proper remedy in rheumatism, and I long ago made use of it in that disorder.

The first time I employed it to a sufficient extent to satisfy myself of 
its superior qualities in such a complaint, was in the month of June, 18:2:3, in the case of S. C., of C., N. H. When I first saw him he was affected with considerable thirst, dry and hot skin, quick and strong pulse, swelled joints in the lower extremities, with redness and tenderness in some parts of them, and extreme pain. The redness and tenderness, together with an inability to move without increasing the pain, induced me to pronounce it acuie rheumatism.

I took from his arm twenty-six ounces of blood, had him so situated in bed as to favor a gentle and long-continued diaphoresis, and administered a powder of opii. grs. ii. gum. camph. pulvis ipecacuan. ài gr. i. every four hours. In a little whille the skin was soft, its heat moderated, and gentle sweating produced, continuing until the cure was effected, which, by keeping ui the opium practice, was accomplished in four or five days. The same pleasurable sensations spoken of by Dr. Webb were experienced to a remarkable degree. I did not confine myself to exactly two grains of opium during the whole time, but varied a little, giving sometimes more and sometimes less, according to circumstances. My object was to keep him under the influence of opium to as high a degree as he would bear.

The next patient that was treated in this way, which 1 shall mention, was J. F., of 'T. It was much such a case is the former, only there was more febrile affection. I have solected this case nostly because before, and at the time my services were called for, he was so prejudiced against opjum as to be unwilling, knowingly, to take it, or have it used in his family. On this account I had to give it to him without his knowledge. The treatment, excepting that the opium was given in larger doses, was exactly the same as in the preceding case. He bad taken it but a slort time ere he began to receive so much benefit from it, and experience such pleasurable sensations, that he was very earnest to have me tell him what he had been taking. I hesitated at first, but on his promising not to be displeased, I told him it was opium. "Well," said he, "if opium has done this, I will never set up my will against it again." By its curing him so suddenly, and leaving him much more healthy afterwards, when in former instances he had been sick three times as long, he could not cense to mention how much his opinion had changed in regard to it.

The case, treated in this way, which has left the next strongest impression upon my mind, was that of a young lady, Miss. M. E., of T. The swelling, pain, and redness, were more changenble from one place to another in this, than in the former cases. The joint or limb that was swollen would be twice as large as that which was not. Sometimes the upper extremities would be most affected, and sometimes the lower. Sometimes the disease would be most severe upon one side, and sometimes upon the other. No part would be entirely free from the affection. Besides the swelling and pain, there was such a soreness upon all the joints and over the whole body, that not even a finger could be moved without a screech. I bled her three times, taking a pint each time. After the third bleeding, the remedial effect of the opium was more apparent than before. The diaphoresis was more regular, the 
swelling more reduced, the pain and soreness more mitigated, and the pleasurable sensations more observable.

In all these cases, the diaphoresis and the pleasurable sensations from the opium, after it had taken effect, were pretty much alike. In all the cases, the treatment in every respect was so satisfactory, that the patients could not help speaking of it at the time and for a long time afterwards. From the happy and satisfactory termination of these cases, I was so applauded, though I speak not of it from ramity, but to show the effect of the medicine, that hundreds of patients, not infected with rheumatism, put thenselves under my care, who would probably have sought for aid from a different source, had it not been for this.

Two other cases present themselves to my recollection, which I should be glad to speak of, but as an account of them would extend my article to too great a length, I shall defer them until another opportunity.

I stated at the commencement of this piece, that I was always favorably disposed towards opium as a curative agent in many disorders. This was not the only thing that induced me to make use of it in rhenmatism. I had a decayed tooth, which, on account of its being so firmly set in my jaw, could not be extracted. 'The pain I suffered fiom it was beyond endurance. I had been troubled with it more or less every day for a month. At length it commenced, one summer evening, just I was retiring to rest, more agonizng and more excruciating than $I$ had ever experienced it before. I flung myself upon my bed, but could get no rest. I got up and walked the room, but it really seemed that if any body ever died with the toothache, I should. I furnished myself with a piece of opium, and bit off a piece as big as a pea, but it did no good. In half an hour I swallowed as much as I did before, but with no better success. The pain continued all night ; I continued walking and screeching, and now and then, without much consideration, biting off and swallowing a piece of opium. I experienced no more effect from it, until daylight appeared, than from a piece of clalk, and then the toothache stopped and the opium began to operate. It had so much effect upon me then, that $I$ called a number of persons and charged them strictly, besides doing some other things, to keep me from going to sleep. By spatting, rubbing, and shaking me, and continually talking to me, they prevented me from falling into what would very likely have been the sleep of death. At length, from some appropriate medicine which I had taken, I commenced voniting, when such a change was produced in my feelings, that I experienced no longer the bad effect of the opium. During that and the next day, I was the happiest creature that ever was. Nothing troubled me, everything appeared to look delightsome, and I had not a moment's pain with the toothache for two years, though I had not been free from it a month at a time for two years before. 'This, and one other circumstance which 1 intend to mention at another time, suggested to me the benefit that might probably be derived from large doses of opium in rheumatism.

Boston, May, 1837.

SAMUfer Fish. 